\title{
高校户籍管理存在的问题及措施
}

\author{
谢璞 \\ 四川大学锦城学院 \\ DOI:10.32629/er.v3i9.3181
}

\begin{abstract}
[摘 要] 在高校开展职能管理工作的过程中,户籍管理是其中一项非常重要的内容,主要借助高校的行 政机关保卫处下属的户籍室或者户籍科来进行。在计划经济时代, 人口的流动性比较小,各个单位的人口 数量也较为稳定; 而如今, 在社会经济不断发展的时代背景下, 社会人口的流动性逐渐增加, 再加上每年 高校扩招导致大学生的数量逐渐增多, 作为接收外来人口的主要单位, 高校的户籍管理工作的重要性也 逐渐体现出来,成为了高校安全管理工作中的基础性内容。鉴于此,本文就高校户籍管理存在的问题及措 施展开探讨, 以期为相关工作起到参考作用。
\end{abstract}

[关键词] 高校户籍管理; 电子户籍信息库; 服务性

中图分类号: D631.42 文献标识码: A

\section{1 高校户籍制度的特点}

与普通的户籍管理制度相比较而言, 高校的户籍管理制度具有如下方面的特 点: (1) 高校户籍管理工作具有阶段性。 学生是高校开展户籍管理服务工作的主 要对象, 新生入学季以及毕业季是高校 户籍管理工作的高峰阶段, 此阶段对户 籍管理工作的质量和效率有着较高的要 求。平常日常管理工作的实施是对学生 或者教职工借用户籍卡进行管理、管理 零散人员办理身份证以及开具落户相关 证明材料。(2) 高校户籍管理工作具有 服务性和管理性。高校户籍室作为学校 的管理部门, 主要职能是对学生和教职 工的户籍档案进行管理。此外, 还承担 着教职工办理身份证以及开具落户相 关证明材料等工作。同时, 高校户籍室 同时也是窗口单位, 是为广大师生员工 提供服务的, 其服务水平以及服务态度 和学校的形象息息相关。(3) 高校户籍 管理工作具有多变性和灵活性的特点 [1]。政府对户籍管控工作的要求比较严 格, 要想外地户口落到学校集体户口, 就应该具备繁琐的手续以及严格的条 件。在市场经济快速发展的时代背景下, 特别是政府需要加大人才吸引战略的 实施力度, 政府对户籍政策比较放松, 落户手续和落户条件也就比较简化。高
校户籍政策也应该和当地政府的户籍 政策相互联系起来, 并且随着政府户籍 政策的变化做出调整。

\section{2 高校学生户籍管理存在的} 问题

2.1 新生入学时户籍迁移工作量大 每年新生在校报到之后, 需要在一 个月的时间内完成 $30 \% \sim 70 \%$ 新生户籍的 迁入工作。在迁入的时候应该手工登记 所有的户籍信息, 并且形成一份户口底 册将其用在立卷档案中, 并且将户口迁 移证、户口底册、本人身份证以及学生 情况登记表等以学院为单位进行整理之 后将其送入属地派出所完成入户迁移的 办理工作。因纯手工操作出现漏登以及 抄错的可能性比较大, 因此, 为了确保信 息的录入准确无误, 就需要花费大量的 时间进行核对, 这样一来就会加剧户籍 迁移工作的繁琐程度 ${ }^{[2]}$ 。

2.2户籍管理手段陈旧、管理模式 落后

将新生的户口迁入到学校之后, 需 要统一将其归集到集体户口中, 将学生 的原生地户口从常住户口转变为挂靠的 集体户口。所有的户籍资料都需要使用 纸片卡登记的方法, 如果学生要补办身 份证, 对原始户籍资料进行查询, 就需要 工作人员从一大堆纸片中逐一进行翻找,
这种方法不仅耗时而且费力。尽管相关 信息都输入到了电脑中, 但是因对其是 简单地使用Excel 电子表的形式进行管 理, 导致信息的录入不够全面。立足于人 口管理和治安管理的角度可以发现, 学 生户籍行政管理工作归属于派出所, 但 是, 因学生户籍资料和日常管理工作无 法提供有效的信息, 导致高校户籍管理 工作存在弊端 ${ }^{[3]}$ 。

2.3 “口袋户口” 现象造成管理方面 的缺失

立足于相关规定, 高校毕业生户籍 工作应该在期限范围内把户口迁入到原 籍或者是迁往工作所在地。从目前的实 际操作看来, 很多学生由于毕业的时候 未能联系好工作单位, 并且自己也不愿 意把户口迁回到原籍, 就把户籍迁移证 放到了自己的“口袋”中, 从而形成了“口 袋户口”, 这样一来也加剧了部分学生在 后期生活以及工作中的不便。比如, 身份 证丢失之后无法进行补办, 结婚、买房不 能提供有效的证明, 出境护照无法办理 等等。与此同时, 因不能联系到毕业生本 人, 按照 “户”、“档” 不可分离的原则, 一些往届生在工作单位继续办理保险, 同时又不得不回到学校把户籍迁回到原 籍, 这样不仅加剧了毕业生的不便, 也给 学校户籍管理工作带来了一定的困难。 


\section{3 全面提升高校学生户籍管理 工作的措施}

3. 1加大学生户籍政策的宣传力度

(1) 新生入学的时候对统一迁移户 口不再硬性规定, 学生立足于自身的实 际情况, 资源对户籍的迁移予以选择。(2) 因受到各种原因的影响, 每年学生退学、 转学、当兵以及休学的数量逐渐增加, 从而加剧了户籍档案保管以及清退工作 的难度。(3) 很多毕业生的户口在两年之 后没能及时进行迁移, 致使学生户籍管 理工作量加剧。对于这种情况, 需要及时 采取合理有效的措施予以完善 ${ }^{[4]}$ 。比如, 应该在新生入学招生宣传材料以及入学 通知书上将户籍迁移的自愿原则标注出 来, 借助学校相关网页对国家的相关户 籍管理政策进行宣传, 这样一来也能够 将户籍迁移给大学生, 为其将其就业提 供便利。

\section{2 运用信息化手段提升管理水平}

作为一个大型的“流动人口集散地”, 学校为了能够简化行事流程, 在新生入 学的时候将迁入到学校的学生户口统一 放在特定的学生集体户口中, 其中, 所有 迁入的学生门牌号和地址都相同, 这样 一来使得居民身份证在使用以及管理工 作中都很难将应有的作用充分发挥出来, 并且也加剧了安全管理工作的难度。因 此, 在依法严格落实管理工作的同时, 需 要做到科学管理, 这也是高校学生有效 落实户籍管理工作的关键, 并且也能够 不断提升服务水平以及工作效率, 使集 体户籍档案管理工作实现电子化, 确保 电子档和纸质档的内容一致, 为查询工
作提供便利, 这样一来也能够给后期电 子信息系统的对接注入新的动力。

3.3 建立完善的学生户籍规章制度

为了能够有效确保学生户籍资料的 正确性以及齐全性, 就需要将相关户籍 办理程序和迁移政策的内容增加到新生 班辅导培训工作中, 以便正确应对学生 的户籍管理问题, 及时做好学生户籍资 料的立档归档管理工作。在学年初期, 需要有效落实新进学生的户籍资料登记 工作, 并且按照院系以及年度分别开展 立卷建档工作。在学年末, 对本届毕业生 的户籍迁移名册, 还需要做好归档作业。 在学期期间, 对于退学或者是应征入伍 的学生的户籍档案, 需要及时对其做出 调整, 并且将原由、日期注明 ${ }^{[5]}$ 。

3. 4 开拓创新学生户籍管理的方法

如今, 大学生的户口迁移办法是借 助高校的居民户口薄和录取通知书到公 安部门直接完成迁移证的办理工作。在 整个社会信息网络化逐渐推进的时代背 景下, 户口迁移工作也将朝着网络化的 管理方向发展。确保户口迁移工作网络 化的有效落实, 能够为户籍资料的准确 性提供良好的条件, 并且也能够有效强 化迁移工作效率。但是, 该项工作的难度 系数比较大, 需要公安部门和高校有效 配合起来最大限度确保户籍管理工作效 率, 这样一来也能够减少人工很对带来 的差错。随着社会经济的快速发展, 城乡 之间的差距逐渐缩小, 对户籍政策国家 也进一步做出了改善, 各个中小型城市 对于户口迁入工作也有了一定的宽限。 因此, 这就要求大学生的户籍管理工作
应该立足于 “暂住式” 的管理模式实施。 可以将高校的学生证和居住证有效配合 起来使用, 等到学生毕业之后确定了居 住地再把户口迁移到居住地或者工作所 在地, 以此来有效节省高校管理、新生入 学以及学生毕业时户口迁移所需的物力 以及人力。

\section{4 结语}

总而言之, 在我国市场经济快速发 展以及人口流动性不断增加的时代背景 下, 特别是随着大城市对人才吸引力度 的不断增加, 户籍政策成为了吸引人才 的主要手段, 高校户籍管理工作应该顺 应时代的发展需要, 其理念应该由“管理 为主, 服务为辅” 逐渐转变为 “以服务为 主, 管理为辅”。只有对管理职能予以弱 化, 强化服务职能, 才能够使户籍政策转 变为促进社会经济发展的助力, 为社会 经济的快速发展提供良好的条件。

\section{[参考文献]}

[1]吉迷.民办高校户籍管理存 在的问题及解决对策 [J]. 智库时代, 2017(16):153-154.

[2]陆学兢.浅谈高校学生户籍管理中 存在的问题及对策[J].才智,2017(30): 170 .

[3]张旭东.高校户籍管理信息化的 探索实践一以对外经济贸易大学为例 [J].北京教育(高教),2014(12):45-46.

[4]金辉.刍议高校学生集体户口的 管理[J].科技展望,2014(20):191.

[5]浦建明.计算机信息技术在高校 学生户籍管理工作中的应用研究 [J].信 息与电脑(理论版),2014(10):60. 